\title{
O agir em Saúde da Família: as condições existentes e necessárias para a interação e a troca de conhecimentos na prática profissional
}

\author{
The acting in Family Health: \\ the existing and necessary conditions for the interaction \\ and knowledge exchange among the professionals
}

Maria Glícia Rocha da Costa e Silva Noronha ${ }^{1}$

Domingos Leite Lima Filho ${ }^{2}$

${ }^{1}$ Prefeitura de Curitiba. Av. Manoel Ribas 2.727, Mercês. 80010-030

Curitiba PR.

mglicia@gmail.com

${ }^{2}$ Universidade Tecnológica

Federal do Paraná.

\begin{abstract}
This paper describes the main conclusions of a research developed from 2005 to 2007 in the Family Health Unit Jardim Pinheiro, in the Sanitary District of Santa Felicidade, Curitiba (PR, Brazil). It was investigated the existing and necessary conditions for the interaction and the knowledge exchange among the professionals of the Family's Health Program (PSF) teams. A descriptive qualitative study has been accomplished, using a half structuralized interview and direct observation as methods of data collection. It has become clear that the investigated PSF's establishment was spread by collective discussion between the directly involved professionals, an evident fact in statements that reveal doubt and insecurity to the introduction of the proposal. It has been verified a distance between what is rank in official regulations and documents about the PSF conception and the reality perceivable organization. Considering this program's conception and practice, it has been verified the importance of thinking and acting on the work processes, operating devices in order to modify technical and social relations in daily team's works, recognizing the different human areas included in the health professional's formation: social, procedural, affectiveness, knowledge, behavior and expression of willingness.

Key words Health, work and education, Family's Health Program, Multiprofessional healthcare team
\end{abstract}

Resumo Este texto relata parte dos resultados de pesquisa realizada no período de 2005 a 2007 na Unidade de Saúde da Família Jardim Pinheiro, no Distrito Sanitário de Santa Felicidade, em Curitiba (PR). Investigaram-se as condições existentes e necessárias para a interação e troca de conhecimentos entre profissionais das equipes do Programa Saúde da Família (PSF). Realizouse um estudo qualitativo descritivo, utilizando a entrevista semiestruturada e a observação direta para coleta de dados. Constatou-se que a implantação do PSF investigado deu-se dissociada de uma discussão coletiva com os profissionais diretamente implicados, fato justificado em discursos que manifestam incertezas e inseguranças quanto à implantação da proposta. Verificou-se um distanciamento entre o que está posto nas regulamentações e documentações oficiais da concepção do PSF $e$ a organização perceptível da realidade. Considerando a concepção e a prática deste programa, verificou-se a necessidade de pensar e agir sobre os processos de trabalho, acionando dispositivos para alterar relações técnicas e sociais presentes no cotidiano do trabalho das equipes, reconhecendo que a formação de profissionais em saúde abrange distintas esferas humanas: social, procedimental, afetiva, do conhecimento, de conduta e de manifestação da vontade.

Palavras-chave Saúde, trabalho e educação, Programa Saúde da Família, Equipe multiprofissional de saúde 


\section{Introdução}

Esta pesquisa inseriu-se na produção de conhecimento sobre a realidade de programas da Atenção Básica à Saúde, buscando contribuir para a identificação e discussão de questões relacionadas ao trabalho e às condições de trabalho. Para seu desenvolvimento, buscaram-se referenciais e concepções sobre processo de trabalho e o trabalho coletivo em saúde, com ênfase na multiprofissionalidade e interdisciplinaridade do trabalho em equipe, na interação e na formação em saúde no contexto do Programa Saúde da Família (PSF).

Nos tópicos a seguir, apresentaremos os elementos referenciais teóricos que orientaram a pesquisa, em especial aqueles relativos aos conceitos de trabalho em saúde, interação e formação em saúde. Em seguida explicitam-se os procedimentos metodológicos seguidos do desenvolvimento da pesquisa, com apresentação sintética dos principais resultados encontrados, concluindo com algumas considerações sobre o estudo realizado e sobre a necessidade de se aprofundarem estudos relativos à temática.

\section{O processo de trabalho, a interação e a formação em saúde}

O ser humano não é algo dado, acabado. Ele é processo, torna-se humano. Primeiramente, produz-se a si mesmo e, ao fazê-lo, se determina como um ser em transformação, fazendo sua história em relação aos outros seres humanos e às condições naturais encontradas em sua épo$\mathrm{ca}^{1}$. Ele produz algo que já estava, antecipadamente, idealizado em sua imaginação, e este fato o diferencia de outros animais; é a dimensão/ concepção ontológica do trabalho ${ }^{2-6}$. Ao realizar o trabalho e atuar sobre essa natureza, transformando-a para satisfazer suas necessidades, transforma-se a si mesmo, sendo produto de seu trabalho num movimento dialético de exploração/ alienação e de criação/emancipação ${ }^{7}$.

Diferentes estudos ${ }^{8-16}$ que abordam o processo de trabalho em saúde afirmam ser ele um trabalho essencial para a vida humana, compartilhando características comuns a outros processos de trabalho, sendo parte do setor de serviços. Funda-se numa inter-relação pessoal intensa, decisiva para a própria eficácia do ato, e possui dimensões intercomplementares e interatuantes ${ }^{11}$. É especial, da esfera não material, centrado no trabalho vivo em ato permanente que se com- pleta na sua realização; seu produto é indissociável do processo que o produz, ocorrendo na própria realização da ação ${ }^{14}$.

Nesse contexto, a adequação entre os processos formativos e a filosofia preconizada para o PSF no Sistema Único de Saúde (SUS) coloca-se como questão central no programa. Os profissionais devem estar inseridos num processo de gestão do trabalho que preconize a educação permanente no trabalho mediante ações concretas direcionadas às necessidades da população, com qualificação profissional que contemple a sociedade, conhecendo, fiscalizando e contribuindo para o fortalecimento do controle social no SUS ${ }^{17}$.

Essas considerações sobre o processo de trabalho e formação dos profissionais de saúde justificam a realização de pesquisas que investiguem a prática da assistência à saúde e o seu desenvolvimento, a formação dos trabalhadores, as articulações destes entre si, as tecnologias disponíveis, os fatores sociais existentes e os fenômenos subjetivos e objetivos que interferem nas atividades desenvolvidas pelas equipes multiprofissionais em Saúde da Família.

O PSF tem se constituído como projeto dinamizador do SUS, pela evolução histórica de organização do sistema de saúde no Brasil. Ele requer reorganização e alta complexidade tecnológica nos campos do conhecimento e desenvolvimento de habilidades e de mudanças de atitudes no cotidiano dos profissionais ${ }^{18-21}$. As relações de trabalho e a formação profissional do trabalhador de saúde são complexas e determinantes na qualificação da Atenção Básica.

O saber do trabalhador é um saber socialmente construído, produto de sua práxis (reflexão-ação) engendrada numa perspectiva em que são inseparáveis os aspectos intelectuais e manuais. A formação do trabalhador como processo de elaboração do conhecimento se constrói no caráter dialético e consciente em torno do poder e da resistência que revestem seus saberes. Assim, os principais desafios para a formação do trabalhador residem em superar visões reducionistas e monolíticas acerca de categorias como educação, trabalho e saúde.

Tendo esses referenciais teóricos como elementos norteadores, a pesquisa teve como objetivo geral investigar as condições existentes e necessárias para a interação e troca de conhecimentos entre os profissionais das equipes do PSF, para a prática do agir em saúde de forma multiprofissional, coletiva e interdisciplinar, visando à integralidade da Atenção Básica em Saúde. 

ne dental, auxiliares de consultórios dentários e agentes comunitários de saúde (Tabela 1). Realizou-se um estudo qualitativo descritivo, utilizando a entrevista semiestruturada com perguntas abertas e fechadas, que foi gravada, e a observação direta para coleta de dados. Seguiu-se a Resolução no 196/96 do Ministério da Saúde. Os sujeitos foram informados e assinaram Termo de Consentimento Livre e Esclarecido.

Foram construídos três eixos de perguntas para responder aos objetivos. Estes eixos favoreceram, durante as análises, a elaboração de categorias e temas em diálogo constante com o referencial teórico. No eixo I, Processo de Trabalho, construíram-se as categorias: Trabalho de cada um e Organização do processo de trabalho. No eixo II, Interação no Trabalho, as categorias: Tra-

Tabela 1. Universo da pesquisa: profissionais das equipes multiprofissionais de Saúde da Família.

\begin{tabular}{lc}
\hline $\begin{array}{c}\text { Especialidade profissional } \\
\text { ou posto de trabalho }\end{array}$ & $\begin{array}{c}\text { Número de } \\
\text { profissionais }\end{array}$ \\
\hline $\begin{array}{l}\text { Profissionais de nível superior (NS) } \\
\text { - Autoridade sanitária }\end{array}$ & 01 \\
- Dentista & 03 \\
- Enfermeiro & 02 \\
- Fisioterapeuta & 01 \\
- Médico & 03 \\
Subtotal & $\mathbf{1 0}$ \\
Profissionais de nível médio (NM) & \\
- Auxiliar de enfermagem & 12 \\
- Agente comunitário de saúde & 12 \\
- Auxiliar de consultório dentário & 05 \\
- Técnico de higiene dental & 02 \\
Subtotal & $\mathbf{3 1}$ \\
Total geral & $\mathbf{4 1}$ \\
Total de profissionais da Unidade de & $\mathbf{4 1}$ \\
Saúde da Família (universo da & \\
pesquisa) & \\
\hline
\end{tabular}

Fonte: Dados da pesquisa "Profissionais das equipes multiprofissionais de saúde - Unidade de Saúde da Família Jardim Pinheiro, Distrito Sanitário de Santa Felicidade, Curitiba (PR), 2007”. tas, auxiliares de enfermagem, técnicos de higie-

A pesquisa ocorreu no período de 2005 a 2007 na Unidade de Saúde da Família Jardim Pinheiro, Distrito Sanitário de Santa Felicidade, em Curitiba (PR). O universo pesquisado foi de 41 profissionais, incluindo médicos, enfermeiros, dentisparc

balho em equipe e Percepções e sentido do trabalho. E no eixo III, Formação em Saúde, a categoria Formação dos profissionais no contexto estudado: o "instituído".

Neste artigo, serão descritos e comentados de forma breve alguns achados das categorias referidas nos eixos considerados mais relevantes para a construção deste texto.

\section{Comentando os resultados}

Dos 41 profissionais de saúde entrevistados, 15\% eram do sexo masculino e $85 \%$ do sexo feminino. $67 \%$ dos profissionais encontravam-se na faixa etária entre 30-40 anos e 33\%, entre 41-50 anos. Todos concursados para cargo efetivo de carreira no serviço público municipal, excetuando-se os agentes comunitários de saúde, que são contratados pela Fundação Assistência Social (FAS/Prefeitura de Curitiba). Quanto à jornada de trabalho, o PSF cumpre uma carga horária de oito horas diárias e quarenta horas semanais.

\section{Eixo I: Processo de Trabalho}

\section{Trabalho de cada um}

A unidade tornou-se PSF em 2001, e essa transformação deu-se "de um momento para o outro". Caracteriza uma implantação do modelo Saúde da Família dissociada de uma discussão coletiva com os profissionais diretamente implicados, fato apontado nos depoimentos seguintes, em que esses profissionais demonstram insegurança e incertezas a respeito do programa. É o que relatam NS3 e NM8:

E então, eu trabalhava nessa mesma unidade de saúde já há três anos, quando de um dia para outro ela se transformou num PSF. Em quatro dias foi definido que ela mudaria de unidade básica para PSF, foi realizado apenas entrevistas com os funcionários e ela mudou. [...] Mas não teve nenhum preparo. (NS3)

Foi tipo assim, ficamos sabendo num dia, e no outro dia a chefe do Distrito veio avisando pra onde cada um tinha que ir. Foi uma entrevista apenas. (NM8)

O processo de seleção, a aplicação ou não de teste seletivo ou concurso para ingresso no PSF está aqui destacada. Os profissionais referem participar de entrevista quando a unidade se "transformou" em PSF. Revela-se tanto certa "informalidade" quanto uma acomodação às contingências do processo; é o que está refletido também nos depoimentos NS3 e NS6: 
Quando aqui "virou” PSF, eu não tinha nem tempo na época para fazer PSF, porque estava com consultório particular, mas a chefe do Distrito me disse: "Você vai ficar." Isso ficou muito confuso e inseguro para mim. Acabou que eu fiquei e já tenho quase concluido cinco anos de PSF. (NS3)

Meu ingresso foi através de uma entrevista e tive muito receio inicialmente de trabalhar no PSF, pois achava que não ia mais "ter jeito" de trabalhar com adulto [...]. Mas eu costumo dizer que "caí de pára-quedas no PSF". (NS6)

Evidenciam-se a incerteza existente no processo de inserção no PSF, o desconhecimento da proposta do programa e, sobretudo, certa fragilidade institucional. No entanto, pelo que comenta o depoente NS1, a garantia de continuidade do trabalho e a "estabilidade profissional" foram atrativos justos para a motivação ao ingresso:

Na primeira oportunidade de trabalhar no PSF, eu não sei se eu não estava preparado, ou por não conhecer exatamente a proposta deste programa é que eu não entrei. [...] Em 1998 eu já estava mais inteirado sobre o programa, sua proposta e tudo, sabia que era uma coisa realmente séria e que não era uma situação que iria iniciar e já acabar. Eu estava também mais seguro e fui aos poucos descobrindo e aprendendo a fazer o PSF. (NS1)

No entanto, vê-se que o desconhecimento sobre o programa em si é motivo de incertezas e inseguranças:

Quando começaram a surgir os PSFs na Prefeitura, eu ia tentar trabalhar no PSF, [...] mas o meu chefe na época me disse que eu não devia ir, pois segundo ele, não se sabia o que se pretendia fazer com o tal do PSF ainda. Na época ele dizia: "Olha, vê o que vocês vão fazer porque esse negócio é meio arriscado..." "Vocês vão ver que é mais complicado que na unidade básica..." [...] Ele dizia isso a todos que queriam ir para o PSF. Daí, ele me pôs medo, e eu desisti. Quando aqui se tornou PSF, fiz a entrevista e passei. Aqueles que tiveram que sair me diziam: "Ai, estou com pena de você." Fui embora daqui apavorada! [...] Quando o pessoal novo chegou, e como eu não conhecia ninguém, apenas sentei num canto e fiquei quieta [...]. Foi tão ruim que no outro dia fiquei doente. Eu tive uma convulsão e foi nervosismo do dia anterior que provocou essa situação. (NM1).

Uma hipótese para essas afirmações talvez seja a precariedade na implantação do PSF, desprovido de amplo diálogo com a comunidade a ser assistida e com os profissionais diretamente envolvidos. Outra é o processo de inclusão no PSF relatado, que também denota a falta de perfil esperado, gerando incertezas.

\section{Organização do processo de trabalho}

Quando solicitado que descrevessem um dia de trabalho no PSF, os depoimentos referiram que o atendimento à demanda era a atividade central, chegando a constituir-se quase como a "razão de ser", seja como objeto, seja como resultado do trabalho em saúde. No entanto, em certos depoimentos, tal dimensão apresentou-se como fator impeditivo de interação dos profissionais; ora era indutora das atividades realizadas pelos trabalhadores, ora causadora de estresse devido à sobrecarga de trabalho.

A demanda aparece como foco da organização do processo de trabalho na unidade e como dificuldade de interação entre os profissionais em NS1 e NS7:

Chego às sete da manhã e corro o dia todo para dar conta da demanda! Não temos muito tempo para trocar para interagir [...]. Ficamos bastante envolvidos na parte clínica tentando dar conta do atendimento ao usuário, e acabamos por ser prejudicados em nossa interação com os membros da equipe. (NS1)

Na avaliação de satisfação do usuário realizada pela secretaria, observou-se que a gente precisava melhorar "mais" no que se refere ao atendimento ao cidadão, encurtando o tempo de espera e aperfeiçoando nossas agendas profissionais. Ou seja, atender em menos tempo mais pessoas. Ninguém quer saber da qualidade, a quantidade é que vale. (NS7)

Traçamos algumas hipóteses para essa situação. A primeira vincula-se à grande carga de trabalho dos profissionais, exclusivamente voltada para o atendimento às demandas mais emergenciais. Desta deriva-se a segunda hipótese, que seria a predominância de iniciativas relativas à organização do processo de trabalho, as quais priorizam o atendimento e relegam objetivos tão importantes quanto a demanda, como a interação e a interdisciplinaridade da atuação a esferas de menor importância.

Uma terceira hipótese, a qual talvez requeira maior atenção, refere-se ao conceito de interação em equipe. Percebe-se que, para os profissionais, esse conceito está diretamente ligado a uma noção de integração do grupo. Consequentemente, eles exercem práticas integracionistas as quais, contudo, estão adstritas a um trabalho que ocorre num espaço formado por um conjunto de pessoas cujas atribuições são tarefas multifunções.

Vejo assim: às vezes temos múltiplas pessoas, com múltiplas funções, trabalhando juntas, sendo puxadas, na verdade, para serem feitos aqueles trabalhos, porque elas estão se sentindo tolhidas e sobrecarregadas. [...] Acho que as pessoas lidam com 
isso como se fosse um campo de treino, onde podem colocar os personagens onde querem e o time tem que jogar. As pessoas não vieram preparadas para serem times de treino, vieram preparadas para serem pessoas, e desenvolver suas habilidades profissionais. Então, sinto a equipe um pouco ressabiada e que administrativamente está muito justa, então não tem para onde escapar. (NS6)

As narrativas seguintes destacam as cobranças, a sobrecarga no trabalho e a carência de profissionais como fatores de desgaste e estresse que dificultam o desenvolvimento das atividades diárias.

O que mais gera LTS é o estresse causado no serviço pela autoridade sanitária. Existem cobranças incabiveis aqui! [...] O que mais judia a equipe não é nem tanto a sobrecarga de trabalho pura e simples; quando faltam pessoas no trabalho, os que estão trabalhando continuam a fazer o trabalho mesmo assim. O pior é o estresse e a pressão de uma supervisão não adequada, principalmente quando estamos com ausência de colegas no trabalho... Isso parece duplicar! (NS2)

A dificuldade tem relação com o número de profissionais das equipes; faltam profissionais de todas as áreas, e com a demanda que cada dia só faz aumentar, acumula e sobrecarrega a todos, em todas as atividades do serviço. (NM6)

\section{Eixo II: Interação no trabalho - as condições necessárias para a troca de conhecimentos}

A categoria Trabalho em equipe ficou dividida nos temas: Trabalho no grande grupo e Trabalho em microárea.

Trabalho em equipe no grande grupo

Os depoimentos revelam uma compreensão limitada do trabalho em equipe. O grupo é caracterizado pela competição e pelo individualismo. A interação ocorre em baixo grau ou, segundo os depoimentos, não ocorre nenhuma interação, colaboração e/ou articulação técnica das ações. De modo geral, os profissionais compreendem o trabalho "em equipe" naquelas situações e especificidades de cada profissão, ou seja, equipes médicas, de enfermagem, odontológica:

Não sei se tem realmente, não podemos dizer que é uma equipe. As pessoas são muito individualistas, isso sim. Vejo isso na enfermagem; mas aqui na "odonto" temos uma "equipe". Também ficamos fechados aqui... Daí temos que nos resolver. (NM1)

Para alguns, no PSF estudado não existem equipes multiprofissionais, mas subequipes fe- chadas, permeadas de ações individualistas. A multiprofissionalidade e a interdisciplinaridade não são percebidas:

Não existe! Os profissionais do grande grupo se fecham, e são completamente individualistas. Teve um período que começou a "ter competição entre as equipes das áreas". Tinha competição de quem mais tirava fotos... de quem atendia mais... Teve até quem mandasse fazer adesivo para pôr na roupa do usuário, e punham adesivo nas atividades dos programas, diferenciando pessoas. [...] Até com relação à divisão de área virou motivo para se competir... Acabou virando uma competição infernal e desagradável, não fazia ninguém crescer, só inimizade... Não existe uma grande equipe que se reúna para trazer resolutividade pro serviço, não existe isso! (NS3)

Uma hipótese sobre a competição fortemente evidenciada aqui poderia ser que o espírito de trabalho em equipe não foi corretamente desenvolvido durante a formação inicial desses profissionais, e ainda que as relações alicerçadas por esse processo pautam-se em ações individualistas e corporativas. Outra hipótese está relacionada à visão idealizada de equipe, a qual se demonstra desprovida de caráter processual de construção grupal, implicando um sofrimento desmedido. Os depoimentos sobre o trabalho em equipe evidenciam todo um conjunto de conhecimentos e mediações presentes na construção da equipe realmente existente e mantêm a fragilidade e insuficiência de explicações baseadas na idealização da equipe.

\section{Trabalho em equipe na microárea}

O relacionamento "entre" os agentes do trabalho em equipe na microárea é permeado de trocas, colaboração, consenso, interação. A interação e a interdisciplinaridade são percebidas pelos trabalhadores nas narrativas NM2 e NM5:

No grande grupo, o trabalho parece que não tem resultado. Já no pequeno grupo, o trabalho flui de outra forma. Não tem competição, todos procuram entrar num consenso e caminham juntos procurando solução aos problemas das pessoas. (NM2)

... a relação que temos no trabalho é totalmente diferente, é maravilhoso... Somos quatro auxiliares de enfermagem e cada uma é responsável por uma área junto com um agente comunitário. $O$ médico e o enfermeiro ficam nos dando apoio quando não resolvemos as situações sozinhas. Trazemos nas reuniões as situações mais complicadas e resolvemos juntos. E aqui eu me sinto no céu. (NM5)

Uma dicotomia nos salta aos olhos com essas narrativas: por que a percepção do trabalho no 
grande grupo da unidade não é vista pelos profissionais como o trabalho desenvolvido na microárea, ou seja, pela pequena equipe? Por que os profissionais parecem referir que o trabalho na microárea parece ser o mundo maravilhoso da interação e produção em saúde, enquanto no grande grupo imperam a competição, a desunião e o individualismo? Pode-se levantar a hipótese, neste caso, de que o grupo interage melhor quanto mais clara a tarefa, como referem os estudos de Pichon Rivière ${ }^{22}$, que caracteriza grupo como conjunto restrito de pessoas ligadas por constante de tempo e espaço, articuladas por mútua representação interna, que se propõe, de forma explícita, uma tarefa que constitui sua finalidade.

Outra hipótese se concentra na confiança interpessoal construída entre os agentes do trabalho em microárea, seja pela afinidade entre eles, seja pela proximidade das relações cotidianas de trabalho. Reconhecer que o trabalho envolve aspectos de extrema importância indica que a responsabilidade pelo resultado aumenta, exigindo maior dedicação por parte dos envolvidos. O depoimento aponta que o trabalho reflete engajamento e complementação:

Cada um tem uma parcela fundamental nesse trabalho. Exemplo é o trabalho do agente comunitário. Vejo-os como uma interface que liga os profissionais de Saúde da Família à comunidade. Se ele não existisse, isso aqui viraria um posto básico. Então o trabalho deles é de extrema importância, assim como a percepção de cada um na equipe: vejo pessoas com uma capacidade de logística fantástica; uns já utilizam isso, é legal de ver como é que eles se arrumam no mundo das coisas e da profissão de cada um. (NS6)

Aqui se aponta uma contradição com estudos recentes sobre o trabalho em equipe no PSF que revelaram ausência de responsabilidade coletiva do trabalho e baixo grau de interação entre as categorias profissionais ${ }^{23}$. Percebe-se que, mesmo timidamente, os profissionais estão agindo com interação e responsabilidade coletiva, avanço bastante positivo.

\section{Percepções e o sentido do trabalho}

O sentido e o significado de criação, transformação, autoria e realização do ser mediante o trabalho são plenamente evidenciados nas narrativas NS1 e NS6:

Eu acho que o trabalho é assim; além de você estar vivendo e fazendo aquilo que você gosta de fazer, de estar botando sua habilidade na prática, é tua satisfação pessoal, é teu crescimento enquanto pessoa, enquanto ser humano. (NS1)
É o local onde eu posso aplicar a minha capacidade, o meu talento, o meu dom. É o local onde posso aplicar o meu conhecimento e talento e que me satisfaz. Mas tem que ser o local em que me sinta satisfeita, feliz com aquilo que estou fazendo, que eu tenha vontade de me desenvolver ali dentro, um local onde eu possa modificar e de alguma forma me modificar também. (NS6)

Em NM8 e NS3, trabalho é entendido como processo e projeto de vida, mediante o qual o ser se faz "a cada dia" e transforma a si e ao mundo; é quando o ser imprime sua marca no mundo:

$O$ trabalho me ensina e me enriquece, me faz melhor. (NM8)

É no trabalho e nas relações que faço aqui dentro que me constituo como pessoa, é meu crescimento pessoal. Tenho certeza que é do meu trabatho que, de alguma forma, vem meu estilo de vida e tudo o que me faz bem. (NS3)

Para NM5, NM7 e NM8, "trabalho da saúde" é diferenciado; envolve empatia e diálogo, estando presentes a emoção, a ansiedade, o sofrimento e a dor. Além disso, o percebem como um processo interativo, como relação e troca, o aspecto relacional da interação entre quem presta e quem recebe a assistência, além de destacar aspectos caracterizadores do trabalho no PSF, como a construção de vínculo e a responsabilidade na relação com o paciente:

Trabalhar na saúde é especial, é troca. Devemos procurar sempre mais conhecimento, pois exige muita reflexão, responsabilidade e construção de vínculo para auxiliar na relação com o paciente, proporcionando eficiência ao cuidado que realizo. (NM5)

É uma ação que não faço sozinha como outra ação qualquer... Existe uma pessoa junto comigo, $e$ para a minha ação dar certo, eu preciso agir com a ajuda dela, é reflexivo e dinâmico, toda hora acontecem coisas... (NM7)

É um trabalho que envolve muita interação entre as pessoas. Você tem que ter empatia com o paciente. Não é a mesma coisa de uma fábrica que faz uma cadeira. Você não vai chorar se a cadeira for embora ou quebrar. Aqui é diferente. São pessoas que estão ali com suas emoções, seus problemas, com seus desejos, seus defeitos. Você conhece a família, a casa dele. (NM8)

Os dados analisados evidenciam a compreensão do trabalho em saúde no sentido ontológico como processo e projeto de vida, mediante o qual o ser se faz "a cada dia"; é quando o ser imprime sua marca no mundo; é também entendido como satisfação das necessidades básicas, como autorrealização e como um processo re- 


\section{Eixo III: Formação em Saúde}

\section{Formação dos profissionais} no contexto estudado: o "instituído"

Os depoimentos acentuam que a formação inicial e continuada está desvinculada do contexto do PSF e da Atenção Básica. Evidenciam que a educação continuada em saúde reproduz o quadro descrito para a graduação. Enfatizam-se especializações que afirmam o modelo mercantilista e elitista de muitas profissões, tendendo a "especializar" mais o especialista no mesmo marco conceitual pedagógico, ratificando um tipo de prática ultrapassado e cada vez mais alienado da realidade nacional. É o que demonstra o depoimento a seguir:

Os cursos que tive auxiliaram somente na parte técnica, da doença clínica mesmo. Só que eu sinto uma deficiência muito grande em termos de sociologia, em termos de psicologia, de antropologia. Nossos cursos ainda só focam tratamento das doenças prevalentes. (NS6)

Em parte, isto se relaciona à não adequação/ atualização dos currículos formativos iniciais, anteriores ao programa Saúde da Família. No entanto, não justifica o fato de a formação continuada desses profissionais permanecer desvinculada do contexto do PSF.

Estamos acostumados atrás do vidro, só restrito na doença, organicista, e apesar de saber do tratamento que existe, muita coisa é psicossomática mesmo, mas só que não temos nenhuma ferramenta externa e interna para enfrentar a realidade lá fora. A prevenção é colocada sempre junto, mas não tem aquilo que tem um treinamento sobre hipertensão, ou que sobre o manejo de uma droga tem. (NS6)

O trabalho envolve tantas coisas, tantas situações que saem da área da saúde, inclusive indo para sociologia, pra antropologia, jurídica, sabe? Mas também é uma coisa técnica, exige muita técnica. (NS7)

Destaca-se a importância de conhecimentos das ciências sociais visando ao enfrentamento das situações cotidianas de trabalho, sendo necessários saberes com aportes e compreensão do significado dos problemas coletivos e individuais de saúde.
$\mathrm{Gil}^{23}$ refere que todos aqueles que atuam em Atenção Básica deveriam compreender os determinantes do processo saúde/doença e agir sobre eles, na definição dos cuidados dos indivíduos e famílias. No entanto, percebe-se que as práticas profissionais impressas pelo modelo biomédico não valorizam tal percepção, limitando-se a práticas pontuais e curativas. Logo, os dados apurados permitem refletir sobre a efetividade das capacitações ofertadas para o desempenho cotidiano dos profissionais da Atenção Básica, ficando evidente a necessidade de mudanças na formação do profissional em saúde.

Redefinir o modelo de formação dos profissionais de saúde, referenciando a realidade social na qual estão inseridos, desenvolvendo também habilidades necessárias ao trabalho no âmbito do SUS, é um fato.

Um modelo de formação orientado pela compreensão crítica das necessidades sociais em saúde, vinculando-se a compreensão dos processos do ciclo de vida dos indivíduos e de suas famílias, a sua repercussão biopsicossocial e cultural, em face da qual se impõe a necessidade do trabalho interdisciplinar à luz de novos paradigmas sobre saúde-doença, revendo-se os papéis e objetivos dos profissionais de saúde no desenvolvimento do agir em equipe - esses pressupostos importam no conteúdo e nas habilidades a serem desenvolvidos e adquiridos pelas capacitações recebidas no cotidiano do trabalho.

\section{Considerações finais}

Como condições existentes, verificou-se que a implantação do PSF investigado deu-se dissociada de uma discussão coletiva com os profissionais diretamente implicados, fato que justifica discursos que manifestam inseguranças e incertezas quanto à implantação da proposta. Conscientes desse distanciamento, os profissionais, quando falam sobre seu trabalho no PSF, se referem às questões concretas do trabalho, porém muitas vezes falam da idealidade do PSF, ou seja, falam de um trabalho ideal no PSF para o real. A concepção de trabalho em equipe que esse trabalhador traz consigo foi construída tendo por referência o PSF ideal que traz a ele expectativas. No entanto, dado que essa idealização traz expectativas difíceis de serem atendidas, o profissional muitas vezes é levado a situações de frustração e sofrimento, tornando-se um trabalhador insatisfeito.

Além disso, o processo de inclusão dos profissionais relatado denota falta de critérios para 
alcançar o perfil esperado para o desenvolvimento das ações no PSF. Esses aspectos causam impactos diversos na configuração e na efetividade do programa, com consequências para a integralidade, a resolutividade de ações, a formação de vínculos e a corresponsabilidade nas ações do programa.

A sobrecarga no trabalho, relatada e observada durante a coleta de dados, se deve a fatores como a falta quantitativa de recursos humanos no serviço e o aumento constante da demanda usuária para o serviço na unidade. Uma evidência em relação ao aumento da demanda usuária: se por um lado ela traz desgaste, estresse e correria no dia a dia do trabalho, por outro ela pode ser um indicativo de que o PSF e a atuação dos profissionais estão sendo reconhecidas e requeridas pela comunidade assistida.

Existe uma tensão permanente entre o modelo de formação biomédica e a prática do agir em saúde, ao tempo que se percebe uma reprodução desse modelo de atenção referido nos discursos dos profissionais. A concepção biomédica da formação dos profissionais tanto está presente na compreensão da comunidade assistida como também se reproduz no interior da própria equipe de saúde. Ou seja, a comunidade do PSF e a sociedade, de certa forma, veneram o modelo médico centrado. A pesquisa evidenciou que a presença dessas concepções na equipe talvez ainda esteja atrelada à formação biomédica dos profissionais. Outra evidência constatada para a manutenção dessa concepção no imaginário social coletivo da sociedade se deve talvez às poucas transformações que ocorreram até o momento no contexto da formação dos profissionais e que, por sua vez, influenciam o contexto sociocultural da sociedade; no entanto, sabese do grande potencial que os profissionais do PSF possuem através da educação em saúde, em atuar como agentes pedagógicos reconduzindo essa concepção junto à sociedade.

A construção, o fortalecimento e a interação do trabalho em equipes podem ser oportunizados durante as reuniões de equipe realizadas, seja nas reuniões de grande grupo, seja naquelas por microárea, por se constituírem espaço concreto para interação e troca de conhecimentos. Essas oportunidades podem ser proporcionadas por gerentes e gestores, através de uma atuação diferenciada de supervisão possibilitando que profissionais sejam capazes de interagir de forma permanente, construindo e reconstruindo dialeticamente novos conhecimentos, ante as peculiaridades locais em que trabalham.
Vivenciar espaços diferenciados de aprendizagem ativa o potencial transformador dos sujeitos implicados, na direção de um entendimento do conhecimento como algo que não apenas conhece as coisas, e sim como algo que pode mudar as coisas $^{24}$. A reflexão sobre o aprendizado diário requer planejamento de atividades com esta finalidade, exigindo, assim, uma aplicabilidade.

É importante reconhecer que a formação de profissionais em saúde abrange distintas esferas humanas: cognitiva, atitudinal, procedimental, social e afetiva e de manifestação da vontade. Junto a mudanças no contexto da formação e da qualificação profissional, destacamos a necessidade premente de se repensar e agir sobre os processos de trabalho, sua gestão, supervisão e autoanálise aliados, pois sem isto nenhuma transformação ou mudança na formação dos profissionais se dará por concreto. É importante observar também a participação dos usuários em busca de seus direitos e de educação à saúde.

Formar sujeitos, utilizando diferentes linguagens, estratégias e recursos, traduz a intenção de desenvolver espaços e cenários formativos que valorizem os sujeitos e seus saberes prévios, assumindo a corresponsabilidade de desencadear reelaborações teórico-práticas que superem o fazer empírico e mobilizem patamares mais complexos de capacidade e atuação profissional, promovendo autonomia, responsabilidade e autoestima.

Destacamos a importância fundamental do papel dos gerentes e gestores como supervisores dessas equipes, de modo a romperem com as próprias matrizes de produção de procedimentos e de gestão do trabalho; lidarem com a divisão técnica e social do trabalho em equipe, buscando um trabalho mais participativo e de respeito às diferenças; apoiarem as equipes na análise das implicações inerentes ao seu processo de trabalho; auxiliarem-nas a lidar com preconceitos e com as preconcepções dos trabalhadores em relação aos usuários e famílias, com a desconstrução da relação poder/saber. Desse modo, fica clara a importância de se desenvolver uma supervisão centrada em práticas político-pedagógicas e não apenas gerenciais. Devemos discutir sem medo a prática que se tem construído entre os profissionais de saúde; o mínimo que poderá acontecer será a construção de novas referências, e mesmo que isso possa atordoar os que se apegam às certezas, parece ser menos danoso que a obediência cega. Só criamos algo novo quando corremos o risco de pôr à prova os paradigmas existentes.

Como trabalhos futuros relacionados ao tema, apontamos a necessidade de realização de 
pesquisas sobre a questão da educação permanente no campo da formação dos profissionais de saúde e das práticas interdisciplinares em equipes multiprofissionais, incluindo aspectos que desvendem como o particular e o coletivo se entrelaçam na prática cotidiana dos serviços de saúde.

\section{Colaboradores}

MGRCS Noronha é responsável pela concepção, interpretação e redação do artigo; DL Lima Filho orientou o estudo original e participou da revisão.

\section{Agradecimentos}

A Amanda Pessoa, pela revisão final do texto.

\section{Referências}

1. Gadotti M. Concepção dialética da educação: um estudo introdutório. 3a ed. São Paulo: Cortez; 1984.

2. Lukacs G. As bases ontológicas do pensamento e da atividade do homem. São Paulo: Ciências Humanas; 1978. (Temas de Ciências Humanas, n. 4).

3. Ianni O. O mundo do trabalho. São Paulo em Perspectiva $1994 ; 8(4): 2-12$.

4. Braverman H. Trabalho e capital monopolista. Rio de Janeiro: Guanabara; 1987.

5. Lukács G. O trabalho. In: Lukács G. Per una ontologia dell'essere sociale. Roma: Editori Riuniti; 1981.

6. Marx K. O Capital. 14a ed. São Paulo: Difel; 1994. v.1.

7. Antunes R. Os sentidos do trabalho: ensaios sobre a afirmação e a negação do trabalho. $5^{\text {a }}$ ed. São Paulo: Boitempo; 2001.

8. Mendes-Gonçalves RB. Medicina e história: raízes sociais do trabalho médico [dissertação]. São Paulo: Faculdade de Medicina da Universidade de São Paulo; 1979.

9. Mendes-Gonçalves RB. Práticas de saúde: processos de trabalho e necessidades. São Paulo: Centro de Formação dos Trabalhadores em Saúde da Secretaria Municipal da Saúde de São Paulo; 1992. (Cadernos Cefor Série Textos, n. 1).

10. Mendes-Gonçalves RB. Tecnologia e organização social das práticas de saúde. São Paulo: Hucitec; 1994.

11. Nogueira RP. O trabalho em serviços de saúde. In: Organização Pan-Americana da Saúde. Desenvolvimento gerencial de unidades básicas do sistema de saúde. Brasília: Opas; 1997.

12. Nogueira RP. O trabalho nos serviços de saúde. In: Santana JP, organizador. Organização do cuidado a partir de problemas: uma alternativa metodológica para a atuação da equipe de Saúde da Família. Brasília: Opas/Representação do Brasil; 2000. p. 59-63.

13. Pires D. Reestruturação produtiva e trabalho em saúde no Brasil. São Paulo: Annablume; 1998.

14. Merhy EE. Saúde: a cartografia do trabalho vivo. São Paulo: Hucitec; 2005.

15. Peduzzi M. Equipe multiprofissional de saúde: a interface entre trabalho e interação [tese]. Campinas: Faculdade de Ciências Médicas, Universidade Estadual de Campinas; 1998.

16. Merhy EE. O ato de governar as tensões constitutivas do agir em saúde como desafio permanente de algumas estratégias. Cien Saude Colet 1999; 4:305-329. 
17. Brasil. Ministério da Saúde. Secretaria de Atenção à Saúde. Departamento de Atenção Básica. Atenção Básica e a Saúde da Família [página na Internet]. Brasília: Ministério da Saúde; 2005. [acessado 2006 ago, para informações de 2005]. Disponível em: http:/ /dtr2004.saude.gov.br/dab/atencaobasica.php

18. Brasil. Ministério da Saúde. Coordenação da Atenção Básica. Manual de organização da Atenção Básica. Brasília: Ministério da Saúde; 1998.

19. Brasil. Ministério da Saúde. Portaria no 648, de 28 de março de 2006. Aprova a Política Nacional de Atenção Básica, estabelece revisão de diretrizes e normas para a Atenção Básica-Programa Saúde da Família (PSF) e o Programa Agentes Comunitários de Saúde (PACS). Diário Oficial da União 2006; 29 mar.

20. Brasil. Ministério da Saúde. Saúde da Família: uma estratégia para a reorientação do modelo assistencial. Brasília: Coordenação de Saúde da Comunidade, Secretaria de Assistência à Saúde, Ministério da Saúde; 1997.

21. Brasil. Ministério da Saúde. Princípios e diretrizes para a NOB/RH - SUS. Brasília: Conselho Nacional de Saúde, Ministério da Saúde; 2002.

22. Pichon-Rivière E. O processo grupal. São Paulo: Martins Fontes; 1991.

23. Gil CRR. Formação de recursos humanos em Saúde da Família: paradoxos e perspectivas. Cad Saude Publica 2005; 21(2):490-498.

24. Demo P. Educar pela pesquisa. $4^{\text {a }}$ ed. Campinas: Autores Associados; 1998.

Artigo apresentado em 5/12/2008

Aprovado em 01/06/2009

Versão final apresentada em 28/07/2009 